\title{
Impact of tropical and subtropical SSTs on mid-latitude tropospheric warming in the northern summer of 2010
}

\author{
Chiaki Kobayashi
}

Received: 2 May 2013/ Accepted: 28 November 2013/Published online: 11 December 2013

(c) The Author(s) 2013. This article is published with open access at Springerlink.com

\begin{abstract}
The relationship between mid-latitude tropospheric warming (MLTW) and the tropical sea surface temperatures (SSTs) in June-August (JJA) of 2010 has been investigated using an atmospheric general circulation model forced with the evolving observed SSTs. The simulation results indicate that the SST anomalies (SSTAs) in the equatorial Pacific in JJA 2010, indicating La Niña condition, did not contribute simultaneously to produce the MLTW in JJA 2010, and, instead, the SSTAs in the northern subtropics (the whole latitudinal band between $10^{\circ} \mathrm{N}$ and $30^{\circ} \mathrm{N}$ ) contributed. However, it is shown by the results that enough magnitude of the atmospheric height anomalies over the northern mid-latitude was not reproduced by the SSTAs over the northern subtropical Indo-western Pacific (IWP) alone or over the northern subtropical Atlantic alone. It implies that both the SSTA over the northern subtropics of IWP and Atlantic were necessary to reproduce the MLTW. The possible role of convective activity for the MLTW is also discussed.
\end{abstract}

Keywords Summer 2010 - Mid-latitude tropospheric warming · Subtropical SST · El Niño response ·

Indo-western Pacific SST · Atlantic SST

\section{Introduction}

The northern summer of 2010 was exceptionally warm over a large area of the mid-latitudes in the Northern Hemisphere. Euro-Russian blocking persisted for more

C. Kobayashi $(\bowtie)$

Climate Research Department, Meteorological Research Institute, 1-1 Nagamine, Tsukuba, Ibaraki 305-0052, Japan

e-mail: ckobayas@mri-jma.go.jp than 1 month, producing an intense heat wave over Eastern Europe and Western Russia in this period (Matsueda 2011). In addition, Japan experienced nationwide record-breaking high temperatures (Tokyo Climate Center News No. 22, available at http://ds.data.jma.go.jp/tcc/tcc/news/). In conjunction with the record-breaking high temperatures, the atmospheric circulation pattern indicated a strongly positive Arctic Oscillation (AO), that is, low pressure in the Arctic and high pressure in the mid-latitudes (Otomi et al. 2012). In relation to the strongly positive AO, the zonally averaged tropospheric air temperature in the mid-latitudes of the Northern Hemisphere was the highest in summer (June-August) since 1979 (Tokyo Climate Center News No. 22). This paper focuses on the mid-latitude tropospheric warming (MLTW) in June-August (JJA) of 2010 as a principal background factor in the hottest summer on record mentioned above, and examines the relationship between the MLTW and tropical sea surface temperatures (SSTs).

The observed atmospheric and oceanic conditions are outlined in Fig. 1. As seen in Fig. 1b, the SST anomalies (SSTA) in the NINO3 region $\left(5^{\circ} \mathrm{N}-5^{\circ} \mathrm{S}, 150^{\circ} \mathrm{W}-90^{\circ} \mathrm{W}\right)$ was decreasing in March-May (MAM) 2010 and became negative in JJA 2010. The La Niña conditions had started in the season. The SSTs over the Indo-Western Pacific region indicated slightly warm anomalies and the SSTAs in the tropical Atlantic Ocean were significantly positive in JJA 2010 (Fig. 1d). The Atlantic significant SSTA had peaked in MAM 2010 and persisted from JJA 2009 to JJA 2010 (not shown). Meanwhile, the geopotential height at $200 \mathrm{hPa}$ indicate remarkable positive anomalies in the latitudinal bands between $30^{\circ}$ and $50^{\circ}$ in the both Hemispheres developed in JJA 2010, after positive anomalies in the tropics occurred during the period January to May 2010 in association with the 2009/2010 El Niño conditions 


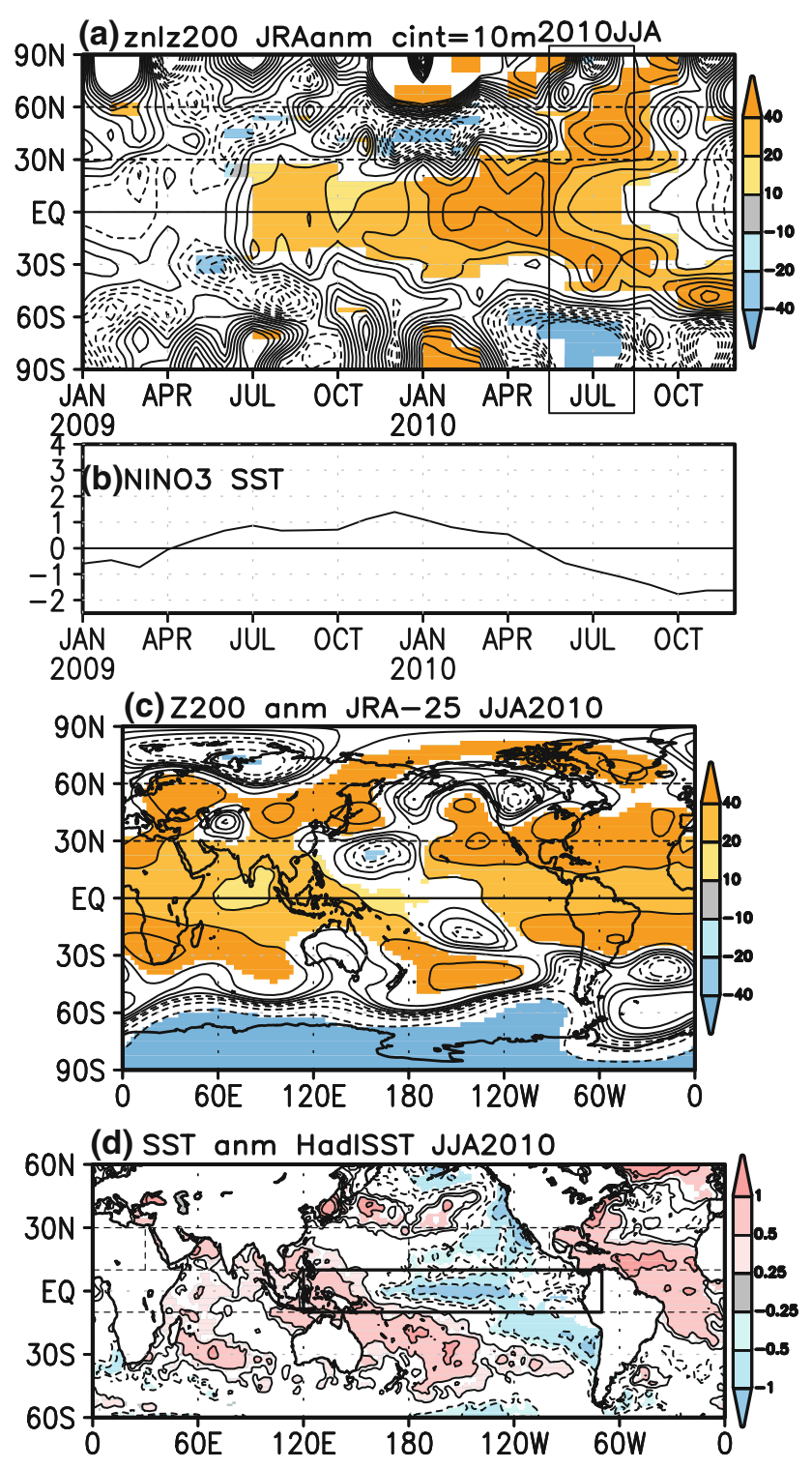

Fig. 1 a Time-latitude section of the observed zonal mean $200 \mathrm{hPa}$ height anomalies (contour interval $10 \mathrm{~m}$ ). b Time series of SSTA in the NINO3 region $\left(5^{\circ} \mathrm{N}-5^{\circ} \mathrm{S}, 150^{\circ} \mathrm{W}-90^{\circ} \mathrm{W}\right)$ from 2009 to 2010. c Three month mean $200 \mathrm{hPa}$ height anomalies in JJA 2010 (contour lines are $\pm 80, \pm 40, \pm 20, \pm 10$ and $0 \mathrm{~m}$ ). $\mathbf{d}$ Three month mean SST anomalies in JJA 2010 (contour lines are $\pm 1.5, \pm 1, \pm 0.5$ and $\pm 0.25 \mathrm{~K})$. The anomalies are departures from the monthly climatology averaged from 1979 to 2009 . The anomalies larger than the monthly standard deviation are shaded. The rectangle in $\mathbf{a}$ is the JJA in 2010. The solid rectangle in $\mathbf{d}$ is the equatorial Pacific region $\left(10^{\circ} \mathrm{N}-10^{\circ} \mathrm{S}, 120^{\circ} \mathrm{E}-70^{\circ} \mathrm{W}\right)$ in this paper

(Fig. 1a). The height anomalies over the tropical latitudes were still positive during JJA 2010. After October 2010, the height anomalies became negative in association with the 2010/2011 La Niña conditions. The evolution pattern of zonally symmetric height anomaly has occasionally been observed during the last three decades. As seen in Fig. 2a, the evolution patterns are particularly evident from 1987 to
1988 and from 1997 to 1998 . In both cases, the MLTW developed in the both Hemispheres, before the tropospheric height anomalies over the tropical latitudes became negative. The geopotential height data are obtained from the Japanese 25-year Reanalysis (JRA-25, Onogi et al. 2007) and the SST data are derived from HadISST1.1 (Rayner et al. 2003). The anomalies are departures from the monthly climatology averaged from 1979 to 2009 . The features of the anomaly pattern shown above are not much affected by long term warming trend.

The fact that tropical tropospheric warming lags one to 3 months behind the peak of the SSTA in the eastern equatorial Pacific (EP) has been documented in many previous studies (e.g., Horel and Wallace 1981; Kumar and Hoerling 2003) as the atmospheric response associated with ENSOrelated SSTAs. The one season lag in the atmospheric response are linked with the temporal evolution of tropical rainfall which lags NINO $3.4\left(5^{\circ} \mathrm{N}-5^{\circ} \mathrm{S}, 120^{\circ} \mathrm{W}-90^{\circ} \mathrm{W}\right)$ SSTA by one season, and the lag in zonal mean tropical rainfall anomalies is linked to the seasonality of the SST variability in the tropical eastern Pacific (Kumar and Hoerling 2003). The tropical warming is accompanied by zonal mean opposite-signed extratropical temperature anomalies in the same time. Seager et al. (2003) suggested mechanisms for the symmetric mid-latitude responses. They pointed out that the transient eddy activity anomalies are important in producing mid-latitude anomalies during ENSO episodes. Moreover, Lau et al. (2005) studied the influence of SSTA in the Indo-Western Pacific (IWP) domain $\left(40^{\circ} \mathrm{N}-40^{\circ} \mathrm{S}, 30^{\circ} \mathrm{E}-\right.$ $165^{\circ} \mathrm{E}$ ) on the extratropical zonal mean temperature during the boreal summer of the year after a peak in ENSO events. Their model results indicated that lagging global scale atmospheric changes are primarily responses to SST perturbations in the IWP in summer, which are linked by the "atmospheric bridge" mechanism to ENSO variability of the eastern EP, peaked in preceding winter.

To confirm the statistical relationship between SSTA distributions and NINO3 SSTAs, the regression and correlation coefficients map of SSTA are shown in Fig. 3. The areas that simultaneously significantly correlated with NINO3 SSTAs in JJA are limited to the eastern EP region (Fig. 3a). The relationship suggest that the SSTAs in the EP region (solid rectangle in Fig. $3 \mathrm{a}, 10^{\circ} \mathrm{N}-10^{\circ} \mathrm{S}, 120^{\circ} \mathrm{E}-$ $70^{\circ} \mathrm{W}$ ) are ENSO-induced SSTAs in JJA. On the other hand, JJA mean SSTA in the tropical and northern subtropical Indian Ocean and the subtropical western North Pacific are significantly positively correlated with preceding DJF mean NINO3 SSTA, which is a half year before the JJA (Fig. 3b). The lagged relationship over the Indian Ocean and the western North Pacific is consistent with the correlation referred to as the Indian Ocean capacitor effect during the summer following El Niño (Xie et al. 2009), which is related to the atmospheric bridge. Since the 

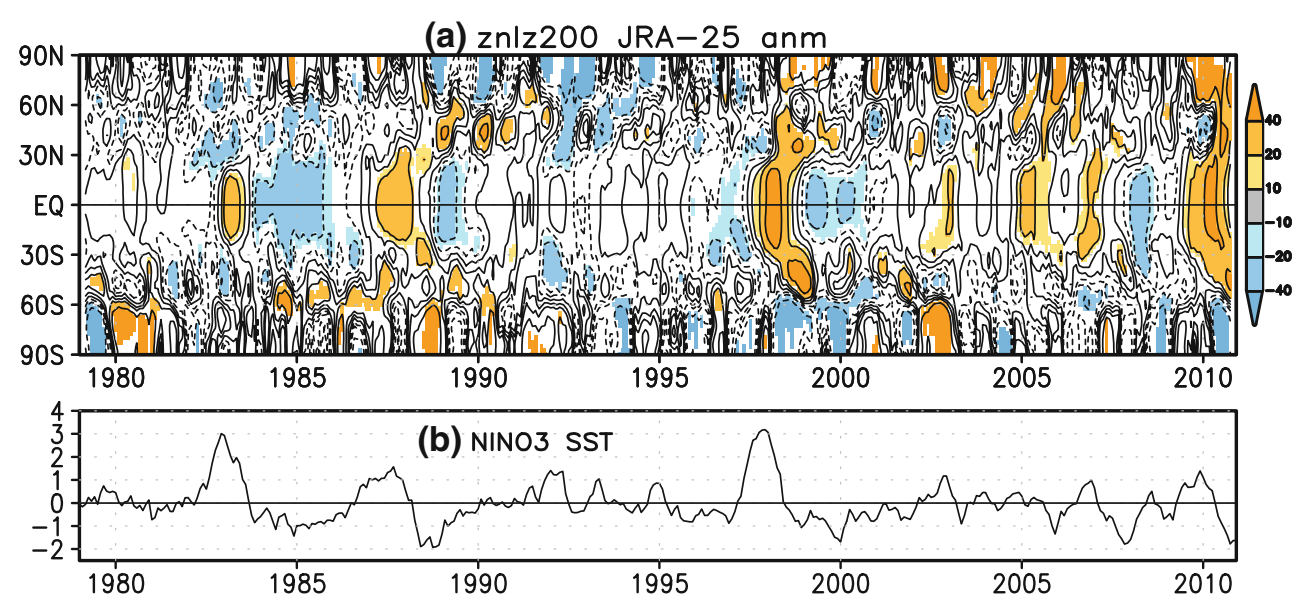

Fig. 2 a Time-latitude section of the observed zonal mean $200 \mathrm{hPa}$ height anomalies smoothed with 5-month running average (contour lines are $\pm 80, \pm 40, \pm 20, \pm 10$ and $0 \mathrm{~m}$ ). b Time series of SSTA in the NINO3 region $\left(5^{\circ} \mathrm{N}-5^{\circ} \mathrm{S}, 150^{\circ} \mathrm{W}-90^{\circ} \mathrm{W}\right)$ from 1979 to 2010.
The anomalies are departures from the monthly climatology averaged from 1979 to 2009 . The anomalies larger than the monthly standard deviation are shaded

might be regarded as a delayed El Niño signals, although the SSTAs are linked to not only ENSO but also the North Atlantic Oscillation (NAO) and a long-term trend, as was pointed out by $\mathrm{Hu}$ et al. (2011).

In the case of the JJA 2010, the areas showing positive SSTA exceeding $+0.5{ }^{\circ} \mathrm{C}$ in the IWP region were limited to the part of the Arabian Sea, the South China Sea and a narrow region along the $30^{\circ} \mathrm{S}$ line in the southern Indian Ocean (Fig. 1d). Since the general relation between midlatitude atmospheric anomalies and SSTAs in the IWP in the boreal summer after the peak phase of ENSO is described by Lau et al. (2005), the MLTW in JJA 2010 might be linked with the SSTAs in the IWP. Problem is whether the SSTAs over the IWP were large enough to produce the MLTW in JJA 2010. Another problem is whether the SSTAs in the North Atlantic Ocean indicating positive anomalies in large area contributed to produce the MLTW in JJA 2010. This study seeks to reveal the impact of SSTAs in the tropics on the MLTW in JJA 2010, using an atmospheric general circulation model forced with the observed SSTs of the period. After indicating the influence of SSTAs in the EP region to the MLTW, the impact of SSTAs in other regions will be shown. The model and experiment setup are described in Sect. 2. The results of the model experiments are presented in Sect. 3. In Sect. 4, the relation between the MLTW in JJA 2010 and convection anomalies linked to SSTAs in the tropical and subtropical regions are discussed. A summary is provided in Sect. 5.

\section{Model and experiment design}

The model used in this study is the atmospheric general circulation model of the Meteorological Research Institute positive SSTAs in the tropical Atlantic Ocean in JJA 2010 
(MRI-AGCM3.2, Mizuta et al. 2011), developed as the atmospheric component of the MRI earth-system model (MRI-ESM1, Yukimoto et al. 2011), which is based on the operational model for numerical weather prediction from the Japan Meteorological Agency (JMA). The MRIAGCM3.2 performs well with respect to the heavy monthly-mean precipitation around the tropical western Pacific, the global distribution of tropical cyclones, the seasonal progress of the East Asian summer monsoon, interannual variability in tropical precipitations, and blockings in the North Pacific (Mizuta et al. 2011). In this study, the AGCM was run at a $\mathrm{T}_{\mathrm{L}} 159$ spectral resolution, corresponding to approximately $125 \mathrm{~km}$ horizontal grid point spacing, with 60 vertical levels and a $0.1 \mathrm{hPa}$ top.

Seven experiments were carried out with different surface boundary conditions. One experiment denoted by ExA is an experiment forced with the observed monthly evolving global SST and global sea ice concentration of HadISST (Rayner et al. 2003). The others are forced partially with observed SSTs in the method described in following paragraphs. Each of the experiment consists of five-member ensembles starting from different initial conditions (1200UTC on 1 and 15 January, 1 and 15 February, and 1 March 2009) taken from JMA operational analysis. All members were integrated until 31 December 2010. Only ensemble-averaged fields of the ensembles are used in this study. The simulated anomalies are shown as departures from the result of control experiment (ExCLIM) performed separately from the experiments described above, which is forced with monthly climatological global SST and sea ice concentration averaged from 1979 to 2009 using the same initial conditions. Because there is a lead time of more than 1 year from each initial date to the focused season, JJA in 2010, the effect of the initial condition in the simulation results can be considered negligible in JJA 2010. In addition, random variation of each member is largely canceled by taking ensemble-average. Hence, the ensembleaveraged anomalies, used for the data analysis here, can be considered as anomalies induced largely by SST anomalies.

To examine the contribution of the EP SST evolution to the MLTW, two experiments were conducted. One is an experiment (Ex1), in which monthly climatological SSTs (1979-1998 mean) were prescribed in the EP region after May 2010, while the observed monthly evolving SSTs were prescribed elsewhere during the experiment period. The SST evolution is depicted schematically in Fig. 4a and the distribution of SST anomalies in JJA 2010 is shown in Fig. 4c. This experiment should answer the question of whether mid-latitude tropospheric height anomalies would have been produced if the ENSO neutral condition had come in the summer of 2010, after the El Niño condition in the previous winter. In another experiment (Ex2), the observed monthly evolving SSTs were prescribed in the EP region after May 2010, while monthly climatological SSTs were prescribed elsewhere during the experiment period. The SST evolution is depicted in Fig. 4b and the distribution of SST anomalies in JJA 2010 is shown in Fig. 4d. The results of the experiment will answer the question of whether the observed SST condition in the EP in JJA 2010 could produce mid-latitude tropospheric height anomalies. The results will indicate how the evolution of SSTs in the EP contributes to zonally symmetric mid-latitude positive height anomalies in JJA 2010.

To identify the area other than EP region where SSTs contribute to the MLTW, four other experiments were performed. The regions, in which the observed evolving SSTs are prescribed, are the equatorial region except for the EP region in the experiment denoted by ExXEP, the whole latitude band $10^{\circ} \mathrm{N}-30^{\circ} \mathrm{N}$ (the northern subtropics) in the experiment ExNSB, the Indo western Pacific part of the latitude band $\left(10^{\circ} \mathrm{N}-30^{\circ} \mathrm{N}\right)$ in ExIWP, and the Atlantic Ocean part of the latitude band $\left(10^{\circ} \mathrm{N}-30^{\circ} \mathrm{N}\right)$ in ExATL. These areas are indicated in Fig. 5 with their specific locations. In these experiments, the observed evolving SSTs were prescribed in the selected areas after May 2010.

\section{Results}

\subsection{Contribution of SSTs in the EP region}

Figure 6a presents a time-latitude section of the simulated zonal mean $200 \mathrm{hPa}$ height anomalies of ExA from 2009 to 2010. Comparing this to the observed data (Fig. 1a), the time evolution of positive anomalies, in which the MLTW (positive height anomalies) appeared after the positive tropical anomalies, are well simulated by the model. The area with positive anomalies more than $40 \mathrm{~m}$ over the tropical latitudes started from November 2009 to May 2010 in association with the 2009/2010 El Niño conditions, although the development of the positive anomalies are proceeding faster than the observation. The positive height anomalies over the mid-latitudes can be seen over the latitudes between $30^{\circ}$ and $50^{\circ}$ in the both Hemispheres for JJA 2010. This result indicates that global SST anomalies contribute to produce symmetric MLTW patterns after positive anomalies over the tropical latitudes.

The spatial pattern of $200 \mathrm{hPa}$ height anomalies in JJA 2010 is shown in Fig. 6d. The observed positive anomalies over the lower latitudes $\left(45^{\circ} \mathrm{N}-45^{\circ} \mathrm{S}\right)$ are well simulated by the model, although the anomalies over the higher latitudes, particularly in the Euro-Russian region, are not represented as significant positive anomalies. The simulated pattern is similar to the simulation by Dole et al. (2011). The observed large height anomalies over the EuroRussian region reflect strong and long-lived blocking event 

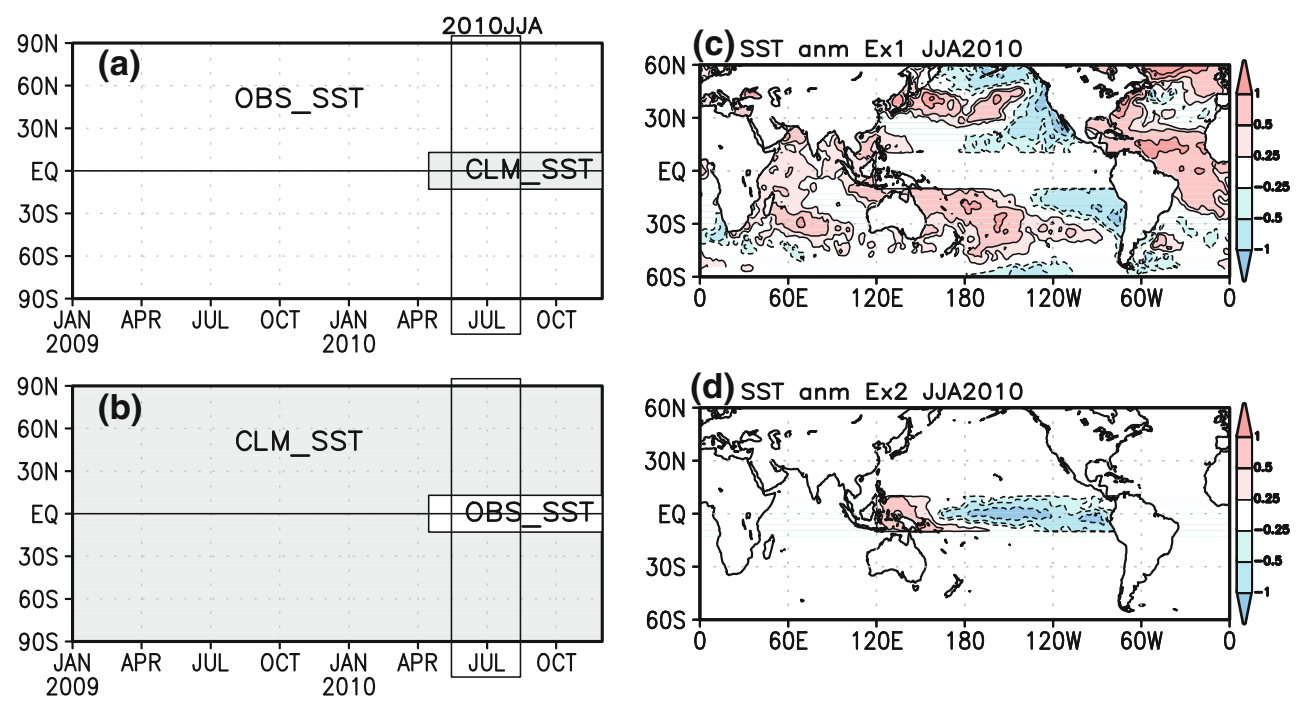

Fig. 4 SST settings of $\mathbf{a} \operatorname{Ex} 1$ and $\mathbf{b}$ Ex 2 at longitude $180^{\circ}$, shown as a time-latitude section, and 3 month mean SST anomalies in JJA 2010 in $\mathbf{c}$ Ex 1 and $\mathbf{d}$ Ex2. The white areas in the left panels indicate the

area in which observed evolving SSTs were prescribed. The shaded area indicates the area in which climatological SSTs were given. The contour lines in right panels are $\pm 1.5, \pm 1, \pm 0.5$ and $\pm 0.25 \mathrm{~K}$

in JJA 2010. As discussed by Dole et al. (2011), it is presumable that the blocking event occurs mainly due to natural internal atmospheric dynamical processes and slowly varying boundary condition did not contribute substantially to the magnitude of the blocking event in JJA 2010. Since the seasonal mean and the evolution pattern of the height anomalies are well simulated over the lower latitudes, the global SST anomalies contribute to produce the anomaly pattern at least in the tropical area and the mid-latitudes.

The simulation results of Ex1 are shown in Fig. 6b, e. The time evolution of positive anomalies, in which the MLTW appeared after the positive tropical anomalies, is well simulated by the experiment. The spatial pattern of seasonal mean height anomalies in JJA 2010 (Fig. 6e) also shows a similar pattern of observation (Fig. 1c) and ExA (Fig. 6d). The well simulated result means that the MLTW would have been generated even if the ENSO neutral condition had came in summer 2010, after the El Niño conditions in winter. In other words, the symmetric MLTW in JJA 2010 is not a response to SST anomalies in the EP region in JJA 2010.

Figure $6 \mathrm{c}, \mathrm{f}$ present the simulation results of Ex2. The time evolution of positive anomalies indicates negative anomalies less than $-20 \mathrm{~m}$ in the tropical latitudes from July 2010 to end of the experiment (Fig. 6c), in association with the $2010 \mathrm{La}$ Niña condition. Corresponding to the negative anomalies, the northern mid-latitude height anomalies are slightly positive in the latter half of JJA 2010. However, the positive anomalies (ensemble mean difference) are not statistically significant, assuming a level of significance of 0.05 , using the ensemble spread of

seasonal mean zonal averaged $200 \mathrm{hPa}$ height, which is estimated as the root mean square difference from the ensemble mean values (Table 1). The result suggests that the SST anomalies in the EP region, indicating La Niña condition in JJA 2010, contributed little to produce MLTW in JJA 2010.

\subsection{Contribution of tropical and subtropical SSTs}

To identify the key region where SSTs contribute to the MLTW, four other experiments were performed. Figure 7 shows simulation results of the four experiments in which observed evolving SSTs were prescribed partially.

The results of the experiment ExXEP (Fig. 7a, e) indicate positive height anomalies over the tropical latitudes during the experiment period, in contrast to Ex2. The positive height anomalies expanded whole tropical area in JJA 2010 (Fig. 7e). The zonally averaged northern midlatitude height anomalies indicate positive in the latter half of JJA 2010, although the seasonal mean value of zonally averaged height anomaly does not indicate statistical significance over the northern mid-latitudes (Table 1). The results of Ex2 and ExXEP suggest that the SSTAs in the equatorial region other than eastern EP region contribute to produce the tropical height anomalies, but do not contribute to produce the MLTW in JJA 2010.

The result of experiment ExNSB (Fig. 7b) represents the MLTW in JJA 2010 in contrast to Ex2 and ExXEP, although the positive anomalies over the tropical latitudes peaked in the spring 2010 are not reproduced well enough. The simulated height anomalies indicates positive in almost the whole northern mid-latitude area other than the 


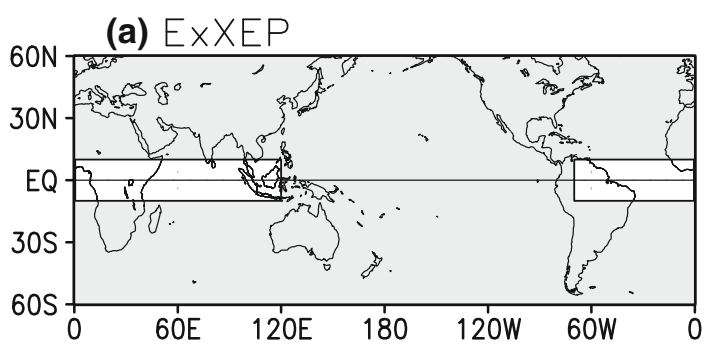

(b) $E \times N S B$

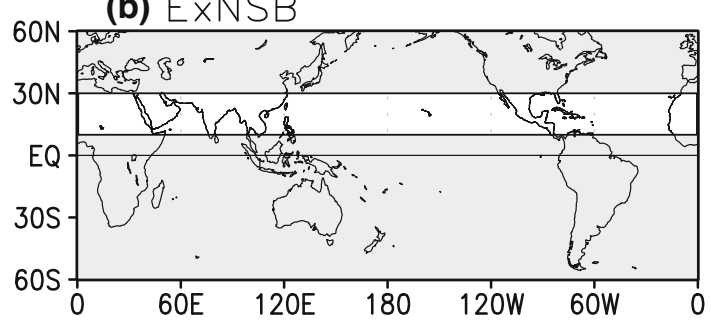

(c) ExIWP

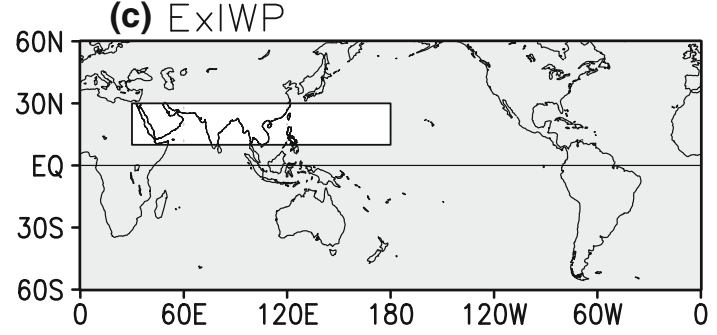

(d) $\mathrm{E} \times \mathrm{ATL}$

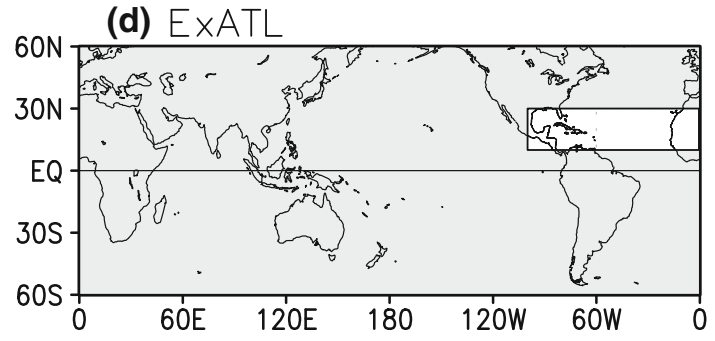

Fig. 5 SST settings of a ExXEP, b ExNSB, $\mathbf{c}$ ExIWP and d ExATL. The white area is where observed evolving SSTs were prescribed after May 2010. Each geographical range is: $10^{\circ} \mathrm{N}-10^{\circ} \mathrm{S}, 0^{\circ}-120^{\circ} \mathrm{E}$ and $10^{\circ} \mathrm{N}-10^{\circ} \mathrm{S}, 70^{\circ} \mathrm{W}-0^{\circ}$ in ExXEP, whole of $10^{\circ} \mathrm{N}-30^{\circ} \mathrm{N}$ in ExNSB, $10^{\circ} \mathrm{N}-30^{\circ} \mathrm{N}, 30^{\circ} \mathrm{E}-180^{\circ}$ in ExIWP, $10^{\circ} \mathrm{N}-30^{\circ} \mathrm{N}, 100^{\circ} \mathrm{W}-0^{\circ}$ in ExATL. The area in which climatological SSTs were given is shaded

Euro-Russian region (Fig. 7f) in common with observation (Fig. 1c), ExA (Fig. 6d) and Ex1 (Fig. 6e). The seasonal mean zonally averaged height anomaly over the northern mid-latitude exhibits statistically significant positive anomalies in ExNSB (Table 1). The result suggests that the SSTA in the northern subtropical latitude contribute to produce the height anomalies in the northern mid-latitude. Interestingly, the positive height anomalies are represented also between $20^{\circ} \mathrm{S}$ and $40^{\circ} \mathrm{S}$ in the ExNSB, although the prescribing observed SSTs covered only in the northern subtropics $\left(10^{\circ} \mathrm{N}-30^{\circ} \mathrm{N}\right)$. This result implies the existence of inter-hemispheric linkages between SSTAs in the northern subtropics and atmospheric conditions in the southern mid-latitude region, which is not further discussed in this paper.

Although the results of the ExIWP (Fig. 7c) and ExATL (Fig. 7d) indicate positive anomalies in the northern midlatitude in JJA 2010, the seasonal mean averaged anomalies (Table 1) are not statistically significant in both experiments. The positive anomalies over the North Africa and Middle East are represented in ExIWP (Fig. 7g) and the positive height anomalies over the southern part of North America and the North Atlantic mid-latitude region are produced in ExATL (Fig. 7h). These results suggest that each of the SSTA in the northern subtropics of IWP and ATL contribute to produce the MLTW in JJA 2010, however enough magnitude of the height anomalies over the northern mid-latitude is not reproduced by the SSTA over the northern subtropical IWP alone or over the northern subtropical Atlantic alone. It implies that both the SSTA over the northern subtropics of IWP and ATL are necessary to reproduce the MLTW in JJA 2010.

\section{Discussion}

In this section, the roles of convective activities in this case are discussed as a connector between SSTs and the atmosphere. Figure 8 depicts the seasonal mean outgoing longwave radiation (OLR) anomalies in JJA 2010 and a simultaneous regression and correlation coefficient map of OLR anomalies with the JJA mean zonal averaged height anomalies over the northern mid-latitudes $\left(30^{\circ} \mathrm{N}-60^{\circ} \mathrm{N}\right)$. The OLR anomalies can be regarded as a proxy for the diabatic heating anomalies in the upper troposphere. In Fig. 8a, negative anomalies, which correspond to enhanced convective activities, exist near Indonesia, and positive anomalies are found in the western equatorial Pacific region. The anomaly pattern is similar to the typical anomaly pattern of an ENSO cold phase. Other areas indicating negative OLR anomalies in JJA 2010 were found near the Arabian Sea, the South China Sea, the Philippine Sea, the Caribbean Sea, and the equatorial Atlantic Ocean. The anomaly pattern over the tropical and subtropical regions is similar to the correlation pattern in Fig. 8b, suggesting that the zonally averaged northern midlatitude heights are closely related to the OLR anomalies in JJA 2010. OLR anomalies in JJA 1988 and JJA 1998, in which MLTWs were remarkable as shown in Fig. 2, were similar to those in 2010 over the Indian Ocean and tropical Pacific, although the anomaly pattern over tropical Atlantic did not show the similar feature to those in 2010.

Figure 9 depicts simulated seasonal mean OLR anomalies in JJA 2010 by the experiments shown in the previous section. The tropical observed OLR anomalies (Fig. 8a) are 

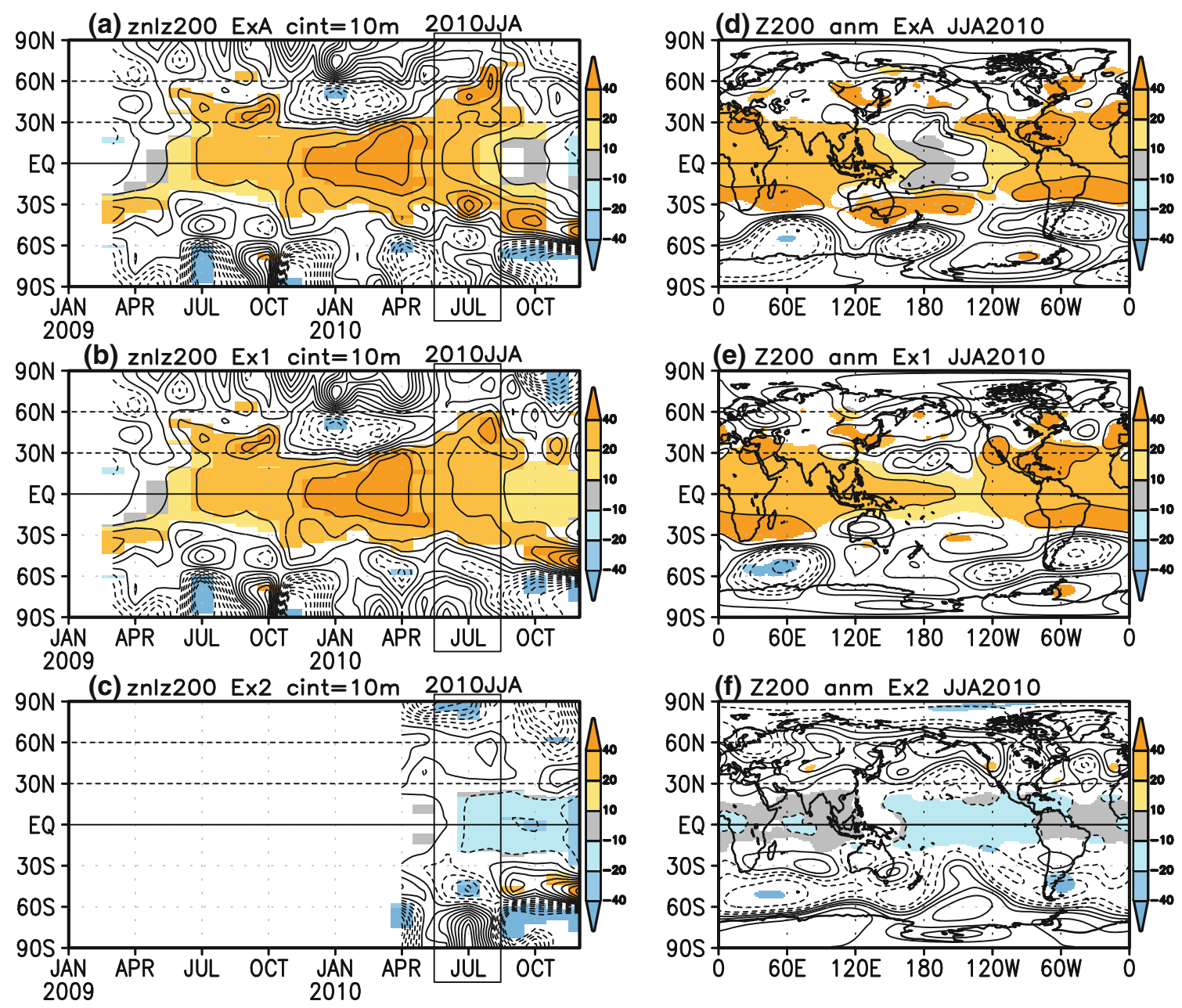

Fig. 6 Time-latitude section of the simulated zonal mean $200 \mathrm{hPa}$ height anomalies of a ExA, b Ex1 and $\mathbf{c}$ Ex2 from 2009 to 2010, and 3 month mean $200 \mathrm{hPa}$ height anomalies of $\mathbf{d}$ ExA, e Ex1 and f Ex2 in JJA 2010. The anomalies are departures from the ensemble averaged $200 \mathrm{hPa}$ height of ExCLIM. The regions indicating

Table 1 Seasonal mean zonal averaged $200 \mathrm{hPa}$ height anomalies and ensemble spread over the northern mid-latitude $\left(30^{\circ} \mathrm{N}-60^{\circ} \mathrm{N}\right)$

\begin{tabular}{lcc}
\hline Experiment & Height anomalies $(\mathrm{m})$ & Ensemble spread $(\mathrm{m})$ \\
\hline ExCLIM & 0.00 & 4.60 \\
ExA & $35.76^{*}$ & 11.27 \\
Ex1 & $31.90^{*}$ & 5.36 \\
Ex2 & 4.74 & 9.08 \\
ExXEP & 4.69 & 6.84 \\
ExNSB & $28.96^{*}$ & 8.23 \\
ExIWP & 11.95 & 10.57 \\
ExATL & $15.27^{*}$ & 8.83
\end{tabular}

The anomalies are departures from the ensemble averaged value of ExCLIM. The ensemble spreads are estimated as the root mean square difference from the ensemble mean values in each experiment. Asterisks indicate ensemble anomalies that are statistically significant, assuming a level of significance of 0.05 statistical significance larger than $95 \%$ level are shaded. The rectangles in left panels indicate the period of JJA in 2010. The contour interval is $10 \mathrm{~m}$ in left panels. The contour lines in right panels are $\pm 80, \pm 40, \pm 20, \pm 10$ and $0 \mathrm{~m}$

well simulated in ExA (Fig. 9a). In the Ex1, the negative anomalies over the Arabian Sea and the Caribbean Sea are well simulated, although the anomalies near Indonesia and the western equatorial Pacific region, which constitute a typical equatorial OLR anomaly pattern of La Niña conditions, are not represented (Fig. 9b). In contrast, the typical equatorial OLR anomaly pattern of La Niña conditions is well simulated in Ex2, although the anomalies over the Caribbean Sea are not represented well (Fig. 9c). Because the MLTW in JJA 2010 is not simulated well in Ex2 but is simulated in Ex1 (Fig. 5b, c), these results of Ex1 and Ex2 suggest that the OLR anomalies over the area other than equatorial Pacific, specifically over the Arabian Sea and the Caribbean Sea, play a more important role in simulating the MLTW than do the OLR anomalies near Indonesia and the western equatorial Pacific region. 


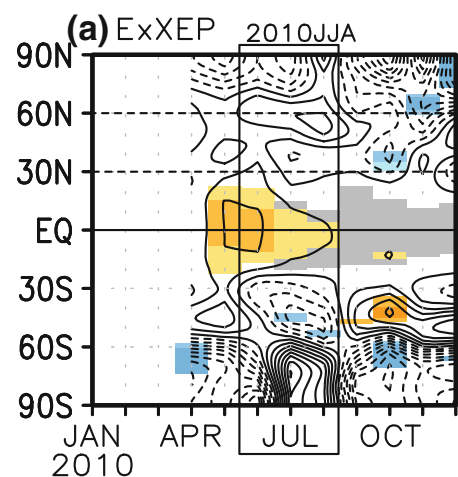

2010

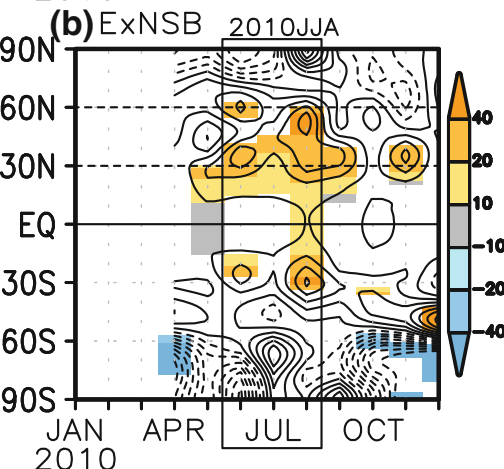

2010

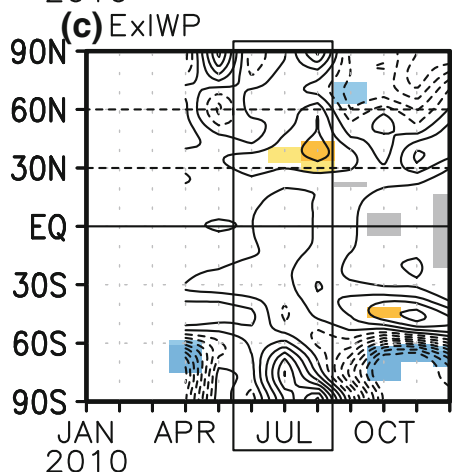

2010

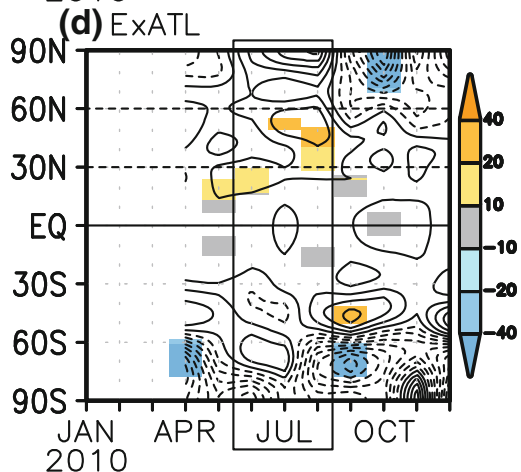

Fig. 7 Time-latitude section of the simulated zonal mean $200 \mathrm{hPa}$ height anomalies of a ExXEP, b ExNSB, c ExIWP and d ExATL from Jan. to Dec. 2010, and 3 month mean $200 \mathrm{hPa}$ height anomalies of e ExXEP, $\mathbf{f}$ ExNSB, $\mathbf{g}$ ExIWP and $\mathbf{h}$ ExATL in JJA 2010. The anomalies are departures from the ensemble averaged $200 \mathrm{hPa}$ height

These conclusions are supported by the results of the ExNSB. The ExNSB does not simulate the equatorial OLR anomaly pattern of La Niña (Fig. 9e), although the (e) Z200 anm EXXEP JJA2010

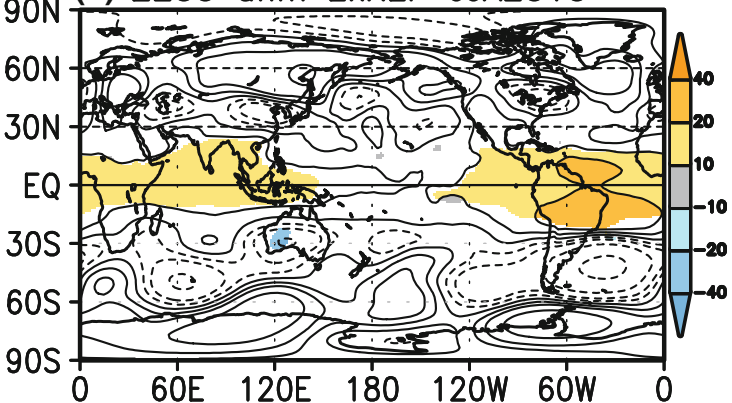

(f) Z200 anm ExNSB JJA2010

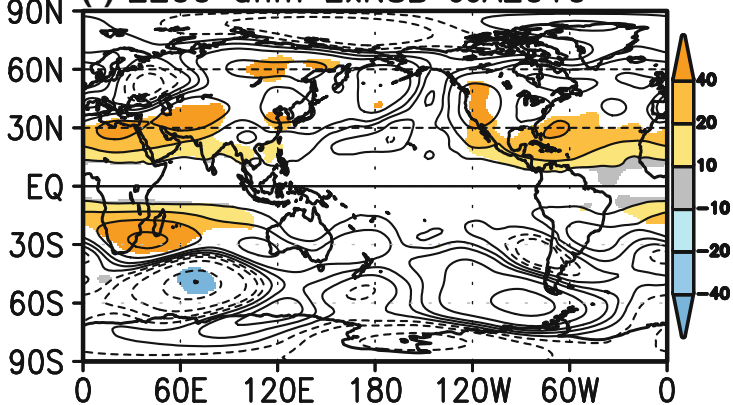

(g) Z200 anm ExIWP JJA2010

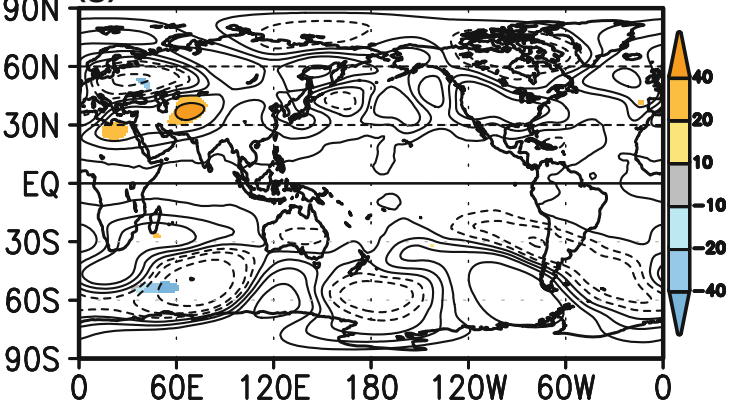

(h) Z200 anm ExATL JJA2010

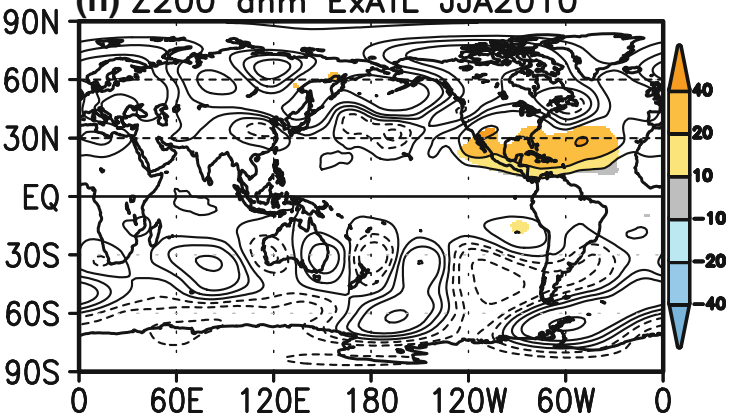

of ExCLIM. The regions indicating statistical significance larger than $95 \%$ level are shaded. The rectangles in left panels indicate JJA in 2010. The contour interval is $10 \mathrm{~m}$ in left panels. The contour lines in right panels are $\pm 80, \pm 40, \pm 20, \pm 10$ and $0 \mathrm{~m}$

experiment does simulate the MLTW (Fig. 7b). The results indicate that the OLR anomalies over the latitude band between $10^{\circ} \mathrm{N}$ and $30^{\circ} \mathrm{N}$ of IWP and the Atlantic Ocean are 


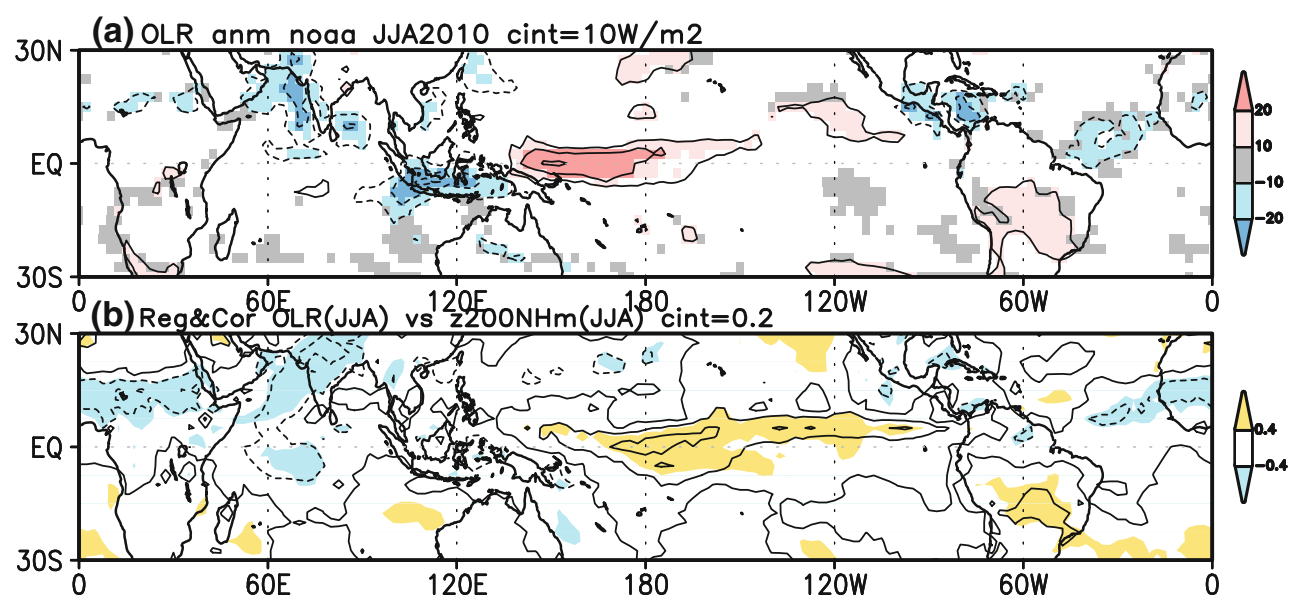

Fig. 8 a Seasonal mean observed OLR anomalies in JJA 2010. The contour interval is $10 \mathrm{~W} \mathrm{~m}^{-2}$. The anomalies larger than the monthly standard deviation are shaded. b Regression (contours) and correlation coefficient (shading) map of JJA mean OLR anomalies with the JJA mean zonal averaged height anomalies over the northern midlatitudes $\left(30^{\circ} \mathrm{N}-60^{\circ} \mathrm{N}\right)$ from 1979 to 2009 . The regression contour interval is $0.2 \mathrm{~W} \mathrm{~m}^{-2} \mathrm{~m}^{-1}$. The regions where correlation coefficients indicate larger than 0.4 and smaller than -0.4 , corresponding to the statistical significance larger than about $95 \%$ level, are shaded. The calculation was performed to the OLR data with linear trend removed

northern mid-latitude area from central Asia to eastern North Pacific mid-latitude region. The areas indicating positive height anomalies over the subtropics and midlatitudes correspond to the observed $200 \mathrm{hPa}$ height anomalies in JJA 2010. Therefore, a part of the observed positive $200 \mathrm{hPa}$ height anomalies over the tropics and lower mid-latitudes (Fig. 1c) can be regarded as response to the diabatic heating anomalies over the subtropics. The wavy response pattern over the Eurasian Continent shows phase shifting from the observation (Fig. 1c) in particular over the Euro-Russian region. The observed wavetrain pattern was triggered by the Russian blocking (Kosaka et al. 2012). The failure of the reproduction of the blocking might be cause of the phase shifting wavetrain response.

Since the amplitude of the response from the heating is not enough in the northern part of the northern mid-latitude, the contribution from transient eddy forcing has been evaluated. Figure 11 presents the seasonal mean zonally averaged anomalies of zonal wind, eddy momentum flux and its divergence at $200 \mathrm{hPa}$ in ExA and ExNSB. The momentum flux convergence area is located from $50^{\circ} \mathrm{N}$ to $70^{\circ} \mathrm{N}$ and the divergence area is found from $25^{\circ} \mathrm{N}$ to $40^{\circ} \mathrm{N}$ in both experiments. The convergence area and the divergence area denote zonal eastward acceleration and westward acceleration, respectively, by transient eddy activities. The eastward (westward) acceleration in $50^{\circ} \mathrm{N}-$ $70^{\circ} \mathrm{N}\left(25^{\circ} \mathrm{N}-40^{\circ} \mathrm{N}\right)$ must be balanced with Coriolis force, thereby inducing northerly (southerly) wind anomalies. The resultant $200 \mathrm{hPa}$ wind convergence around $45^{\circ} \mathrm{N}$ is compensated by anomalous descent, which induces adiabatic warming. This adiabatic warming is balanced by ica. The wavy anomaly pattern is also represented in the 
(a) OLR anm ExA JJA2010 $\operatorname{cint}=10 \mathrm{~W} / \mathrm{m} 2$
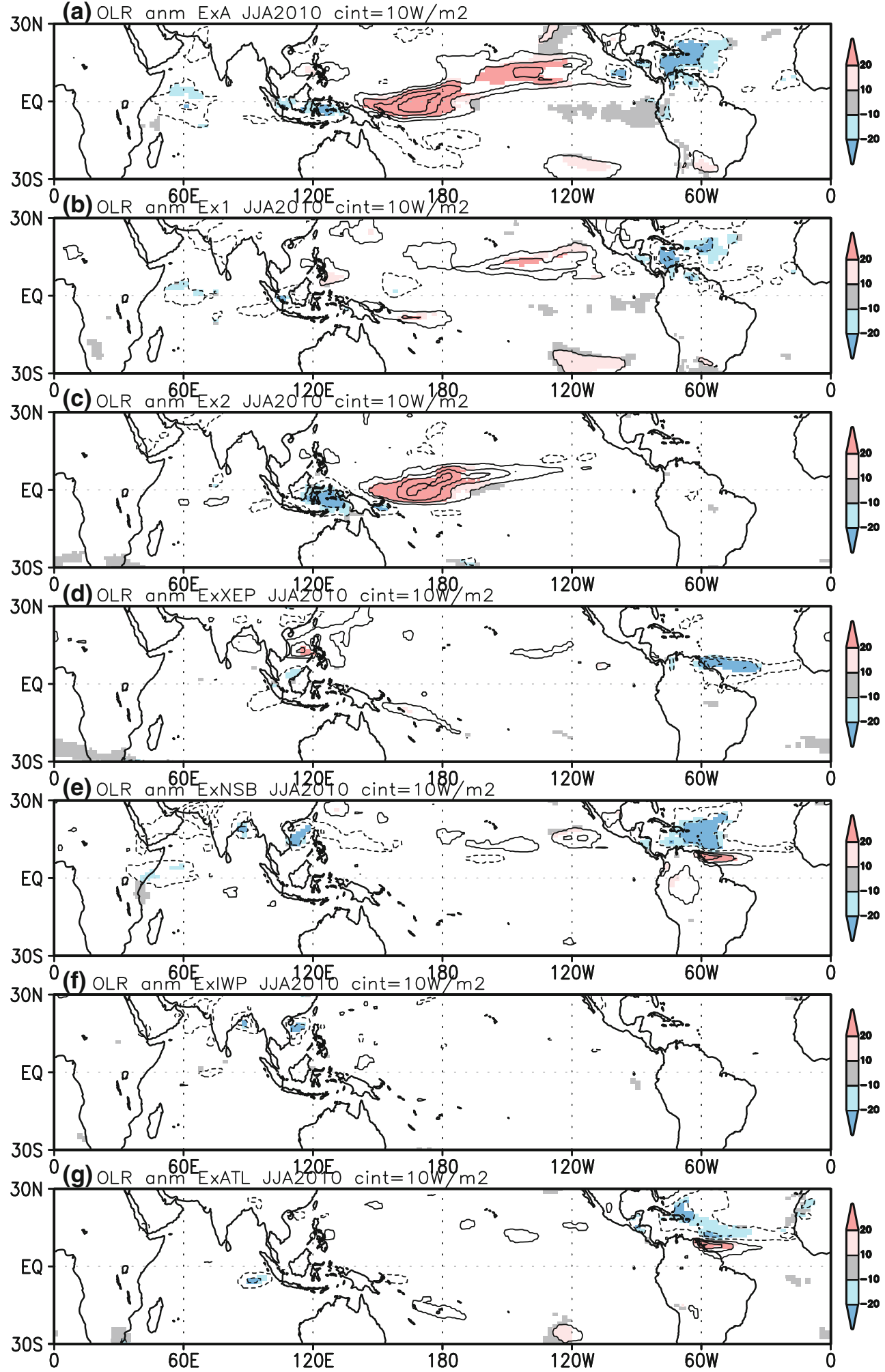

Fig. 9 Seasonal mean simulated OLR anomalies in JJA 2010. a ExA, b Ex1, c Ex2, d ExXEP, e ExNSB, f ExIWP, g ExATL. The anomalies are departures from the ensemble averaged OLR of diabatic cooling (presumably increased radiative cooling), and consequently the warm anomalies are induced in the mid-latitude as pointed out by Seager et al. (2003). They
ExCLIM. The contour interval is $10 \mathrm{~W} \mathrm{~m}^{-2}$. Shading indicates statistical significance larger than $95 \%$ level

explained that this mechanism works in the mid-latitude warming during La Niña event. However the ExNSB indicate similar anomaly pattern of the transient eddy 
Fig. 10 a $200 \mathrm{hPa}$ height response in LBM with prescribed heating over the Arabian Sea and the Caribbean Sea, and $\mathbf{b}$ its zonal averages. Heating areas in a are heavily shaded. The maximum of the heating is $6 \mathrm{~K}$ per day at $450 \mathrm{hPa}$, typical of deep convection (a) IND and ATL Response Z200

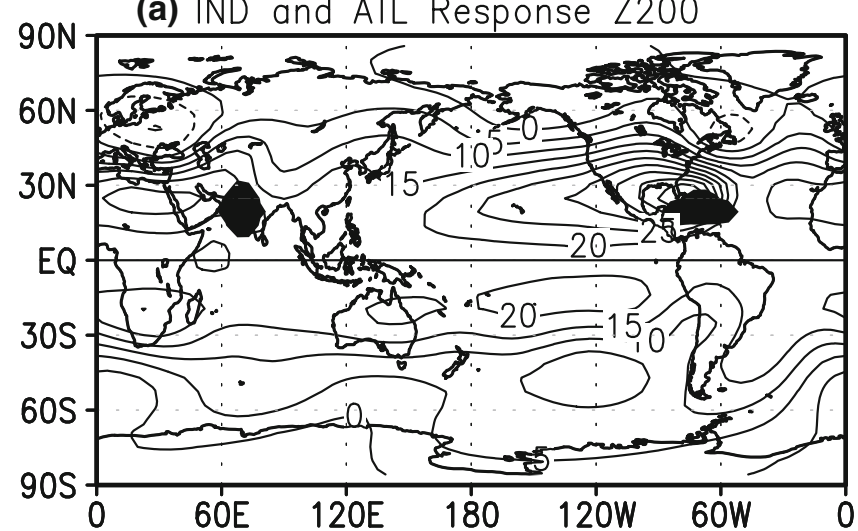

(b) $z n \mid Z 200$

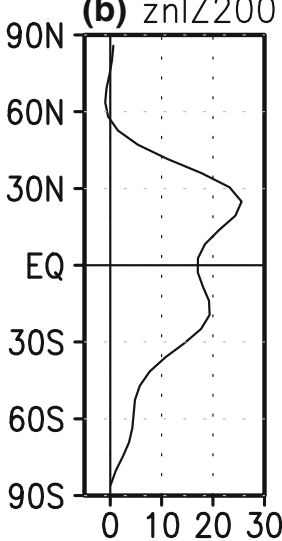

(a) znl u200 anm ExA

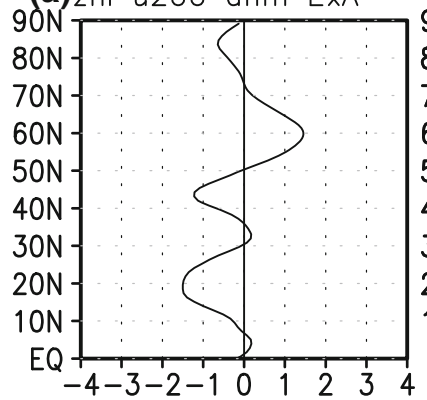

(c) znl u200 anm ExNSB

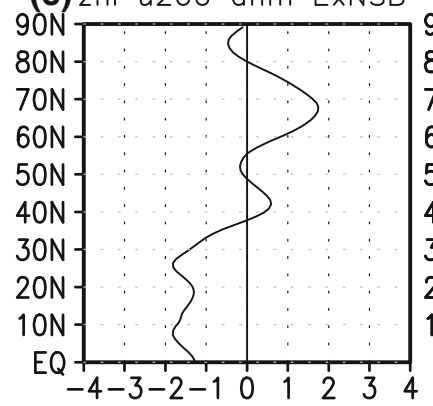

(b) znl mf\&divmf ExA

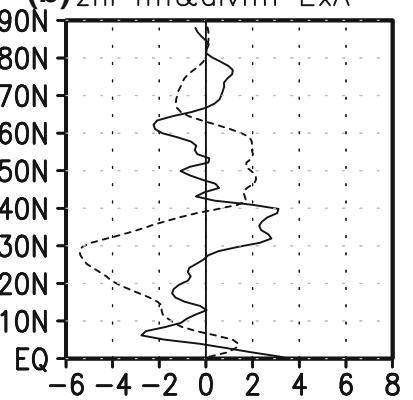

(d) znl mf\&divmf ExNSB

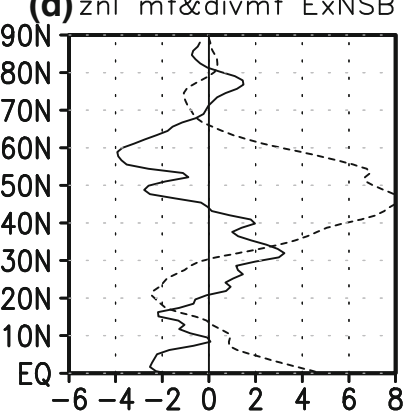

Fig. 11 a Simulated anomalies of the seasonal mean zonally averaged $200 \mathrm{hPa}$ zonal wind in JJA 2010 in ExA. The anomalies are departures from the ensemble averaged $200 \mathrm{hPa}$ zonal wind of ExCLIM. b Simulated anomalies of the seasonal mean zonally averaged $200 \mathrm{hPa}$ eddy momentum flux (broken line unit $\mathrm{m}^{2} \mathrm{~s}^{-2}$ ) and its divergence (solid line unit $10^{-6} \mathrm{~m} \mathrm{~s}^{-2}$ ) in JJA 2010. c Same as a but in ExNSB. d Same as b but in ExNSB

momentum flux divergence without any SST anomalies in the EP region. The result suggests that SSTAs in the subtropics induce transient eddy forcing anomalies. Therefore, eddy momentum flux might contribute to produce positive height anomalies over the northern mid-latitudes.

\section{Summary}

The relationship between MLTW and tropical and subtropical SSTs in JJA 2010 has been investigated in this

study. The simulation results indicated that (1) the SSTAs in the EP region, indicating La Niña condition, did not contribute simultaneously to produce the MLTW in JJA 2010, (2) the SSTAs over the equatorial area other than EP region contribute to produce the atmospheric warming over the tropical region, (3) the SSTAs in the northern subtropical region work to produce the MLTW, although enough magnitude of the anomalies was not reproduced by the SSTAs over the northern subtropical IWP alone or over the northern subtropical Atlantic alone. The subtropical ocean warming over the IWP in the JJA 2010 was typical for El Niño events. In addition, the SSTAs in the tropical Atlantic Ocean are significantly positive in JJA 2010. The significant positive SSTAs over the Atlantic Ocean probably linked with NAO which indicate large amplitude in the previous winter.

In response to SST anomalies in subtropics, the observed convective activities were stronger than normal in the IWP and Atlantic in JJA 2010. The heating anomalies in the northern subtropics might be one of the causes of the observed large height anomalies in the mid-latitudes in JJA 2010, at least in the southern part of the northern midlatitudes, because the experiments simulating MLTW indicate common characteristics representing positive convective activities in the IWP and Atlantic. However, the contribution of eddy-driven circulation might be necessary to produce the northern part of the northern MLTW.

Although the northern MLTW was remarkable as explained above, such a tropospheric warming has not always occurred in JJA of the year after the peak of El Niño events (Fig. 2). Further investigations related to the air-sea interaction over the Indian Ocean and Atlantic Ocean are required to clarify the different response in the extratropics, as well as investigations related to transient eddies in the mid-latitudes.

Acknowledgments The author thanks Dr. M. Watanabe for permitting the use of the LBM, and is grateful to our MRI colleagues for helping to use their AGCM. The author is also grateful to the 
members of the Climate Prediction Division of JMA for their helpful advice clarifying certain issues in this article.

Open Access This article is distributed under the terms of the Creative Commons Attribution License which permits any use, distribution, and reproduction in any medium, provided the original author(s) and the source are credited.

\section{References}

Dole R, Hoerling M, Perlwitz J, Eischeid J, Pegion P, Zhang T, Quan XW, Xu T, Murray D (2011) Was there a basis for anticipating the 2010 Russian heat wave? Geophys Res Lett 38:L06702. doi:10.1029/2010GL046582

Horel JD, Wallace JM (1981) Planetary-scale atmospheric phenomena associated with the Southern Oscillation. Mon Weather Rev 109:813-829

Hu Z-Z, Kumar A, Huang B, Xue Y, Wang W, Jha B (2011) Persistent atmospheric and oceanic anomalies in the North Atlantic from Summer 2009 to Summer 2010. J Clim 24:5812-5830. doi:10. 1175/2011JCLI4213.1

Kosaka Yu, Chowdary JS, Xie SP, Min YM, Lee JY (2012) Limitations of seasonal predictability for summer climate over East Asia and the Northwestern Pacific. J Clim 25:7574-7589

Kumar A, Hoerling MP (2003) The nature and causes for the delayed atmospheric response to El Niño. J Clim 16:1391-1403

Lau NC, Leetmaa A, Nath MJ, Wang HL (2005) Influences of ENSOinduced Indo-Western Pacific SST anomalies on extratropical atmospheric variability during the boreal summer. J Clim 18:2922-2942

Matsueda M (2011) Predictability of Euro-Russian blocking in summer of 2010. Geophys Res Lett 38:L06801. doi:10.1029/2010 GL046557

Mizuta R, Yoshimura H, Murakami H, Matsueda M, Endo H, Ose T, Kamiguchi K, Hosaka M, Sugi M, Yukimoto S, Kusunoki S, Kitoh A (2011) Climate simulations using MRI-AGCM3.2 with 20-km grid. J Meteorol Soc Jpn 90A:233-258. doi:10.2151/jmsj. 2012-A12

Onogi K, Tsutsui J, Koide H, Sakamoto M, Kobayashi S, Hatsushika $\mathrm{H}$, Matsumoto $\mathrm{T}$, Yamazaki S, Kamahori H, Takahashi K,
Kadokura S, Wada K, Kato K, Oyama R, Ose T, Mannoji N, Taira R (2007) The JRA-25 reanalysis. J Meteorol Soc Jpn 85:369-432. doi:10.2151/jmsj.85.369

Otomi Y, Tachibana Y, Nakamura T (2012) A possible cause of the AO polarity reversal from winter to summer in 2010 and its relation to hemispheric extreme summer weather. Clim Dyn 40:1939-1947. doi:10.1007/s00382-012-1386-0

Rayner NA, Parker DE, Horton EB, Folland CK, Alexander LV, Rowell DP, Kent EC, Kaplan A (2003) Global analyses of sea surface temperature, sea ice, and night marine air temperature since the late nineteenth century. J Geophys Res Atmos 108(D14):4407. doi:10.1029/2002JD002670

Seager R, Harnik N, Kushnir Y, Robinson W, Miller J (2003) Mechanisms of hemispherically symmetric climate variability. J Clim 16:2960-2978

Uppala SM, Kållberg PW, Simmons AJ, Andrae U, da Costa Bechtold V, Fiorino M, Gibson JK, Haseler J, Hernandez A, Kelly GA, Li X, Onogi K, Saarinen S, Sokka N, Allan RP, Andersson E, Arpe K, Balmaseda MA, Beljaars ACM, van de Berg L, Bidlot J, Bormann N, Caires S, Dethof A, Dragosavac M, Fisher M, Fuentes M, Hagemann S, Hólm E, Hoskins BJ, Isaksen L, Janssen PAEM, McNally AP, Mahfouf J-F, Jenne R, Morcrette J-J, Rayner NA, Saunders RW, Simon P, Sterl A, Trenberth KE, Untch A, Vasiljevic D, Viterbo P, Woollen J (2005) The ERA-40 re-analysis. Q J R Meteorol Soc 131:2961-3012. doi:10.1256/qj. 04.176

Watanabe M, Kimoto M (2000) Atmosphere-ocean thermal coupling in the Northern Atlantic: a positive feedback. Q J R Meteorol Soc 126:3343-3369. doi:10.1002/qj.49712657017

Watanabe M, Kimoto M (2001) Corrigendum. Q J R Meteorol Soc 127:733-734. doi:10.1002/qj.49712757223

Xie S-P, Hu K, Hafner J, Tokinaga H, Du Y, Huang G, Sampe T (2009) Indian Ocean capacitor effect on Indo-Western Pacific climate during the summer following El Niño. J Clim 22:730-747. doi:10.1175/2008JCLI2544.1

Yukimoto S, Yoshimura $\mathrm{H}$, Hosaka M, Sakami T, Tsujino $\mathrm{H}$, Hirabara M, Tanaka TY, Deushi M, Obata A, Nakano H, Adachi Y, Shindo E, Yabu S, Ose T, Kitoh A (2011) Development of the Meteorological Research Institute-Earth System Model (MRIESM1)-model description. Technical reports of the Meteorological Research Institute, No 64. MRI, Tsukuba, p 88 